\title{
Increasing Knowledge, Attitudes, Skills, and Glucose Control in Type-2 Diabetic Patients through EMAS Interventions
}

\author{
Arief Andriyanto $^{1}$, Etty Rekawati ${ }^{2}$, Dwi Cahya Rahmadiyah ${ }^{2}$ \\ ${ }^{1}$ Department of Community Nursing, STIKes Bina Sehat PPNI Mojokerto, Indonesia \\ ${ }^{2}$ Department of Community Nursing, Faculty of Nursing, University of Indonesia, Indonesia \\ Corresponding Author: Arief Andriyanto (ners.arif91@gmail.com)
}

Received: 3 May 2019

Revised: 21 October 2019

Accepted: 27 December 2019

\begin{abstract}
Background: Diabetes Mellitus (DM) is a chronic and non-communicable disease that has serious impacts. Previous studies have focused on a single intervention in the management of DM. Therefore, EMAS (education, nutrition management, physical activities, and stress management) interventions are proposed to convey the pillars of diabetes mellitus as endorsed by the Indonesian Ministry of Health.

Purpose: This study aimed to analyze the effects of EMAS interventions on the knowledge, attitudes, skills, and glucose control in patients with type-2 DM.

Methods: This study used a pretest-posttest quasi-experimental design without control groups. The samples were 86 diabetic patients recruited using a purposive sampling technique. The EMAS interventions were conducted for six months and eight sessions (October 2018 to March 2019). The EuroQoLfive-dimensional (EQ-5D) questionnaire was used to collect the data, and the paired t-test was used for data analysis.

Results: The results showed that there were significant differences in the knowledge, attitudes, skills $(p=0.001)$, and glucose control $(p=0.04)$ of type 2 diabetes mellitus after the implementation of EMAS interventions.

Conclusion: EMAS interventions significantly increased the knowledge, attitudes, and skills in patients with type 2 diabetes to behave healthier to control their blood sugar. Community nurses can use EMAS intervention for the management of DM among diabetic patients.
\end{abstract}

Keywords: Knowledge; attitudes; skills; glucose control; type-2 diabetes mellitus

How to cite: Andriyanto, A., Rekawati, E., \& Rahmadiyah, D.C. (2019). Increasing knowledge, attitudes, skills, and glucose control in type-2 diabetic patients through EMAS interventions. Nurse Media Journal of Nursing, 9(2), 141-150. doi:10.14710/nmjn.v9i2.22989

Permalink/DOI: https://doi.org/10.14710/nmjn.v9i2.22989

\section{BACKGROUND}

International Diabetes Federation (IDF) shows that there are 415 million people in the world in 2015 who are diagnosed having diabetes mellitus (DM), and the organisation predicts that in 2040, the disease will increase to 642 million (Ministry of Health Republic of Indonesia, 2016). In addition, World Health Organization (WHO) stated 
that in 2004 there were around 194 million people experience diabetes and the organisation forecasted that the total number would reach 333 million people in 2025, with the largest populations are in Asia and Oceania (Ayele, Tesfa, Abebe, Tilahun, \& Girma, 2012; Mohebi, Parham, Mozafarion-Pour, \& Kamran, 2014). Adult people who have diabetes in Southeast Asia in 2015 are 8.5\% (Jeong \& Yu, 2018). Meanwhile, Indonesia contributes a substantial prevalence related to the increase in persons with diabetes from 2007 to 2018. The Basic Health Research (Riskesdas)'s data showed that the total number of people living with diabetes was $5.7 \%$ in 2007 , and $8.5 \%$ in 2018 (Ministry of Health Republic of Indonesia, 2018). Therefore, the phenomenon requires management programs for glucose control.

Diabetes mellitus can be controlled by self-management behaviours, such as providing health education, having nutrition management (meal planning or diet), doing regular physical activities to reduce the overweight, taking pharmacological interventions that regularly take medication/insulin, monitoring blood sugar levels routinely, doing foot care, and taking stress management (Joiner, Nam, \& Whittemore, 2017; Wattanakul, 2012). Besides, maintaining blood glucose levels within normal limits is very important in the management of diabetes mellitus. Diet is an effective way which has a significant impact to stabilise the blood glucose levels (Al-Khalifa, Mathew, Al-Zaid, Mathew, \& Dashti, 2009).

The latest findings of a study that is based on social-cognitive theories find that physical activities in women who have diabetes mellitus are useful to increase self-efficacy (Ahdizadeh, Peymam, Taghipour, Esmaily, \& Mahdizade, 2013). A study which was conducted on the factors that influence self-management of adults who experienced type 2 diabetes, in Malang City, East Java, shows that a factor which can improve selfefficacy and self-awareness of people living with diabetes is to achieve good selfmanagement behaviours, such as having a healthy diet, exercising regularly, monitoring the blood sugar levels actively, taking medication regularly, and doing foot care (Dwi, Amatayakul, \& Karuncharernpanit, 2017). Fan, Cde, and Sidani (2018) point out that Diabetes Self-Management Education (DSME) plays a vital role in empowering people with diabetes to engage and maintain the lifestyle changes, which have been proven enable to improve the health quality. DSME is a process of facilitating knowledge, attitudes, and abilities needed for self-management.

Darling-Fisher, Kanjirath, Peters, and Borgnakke (2015) state that nursing interventions have focused on the pillars of managing diabetes mellitus. It means that innovation is needed for service providers specifically to educate diabetic patients about the need for appropriate preventive care through a community-based approach. Health promotion activities in many studies have been stated as determinants of a person's behaviour, so health promotion will be an essential factor in promoting healthy behaviour (Lari, Tahmasebi, \& Noroozi, 2017; Wang, Ou, Tsai, Chang, \& Kao, 2016). Services that are provided in a comprehensive and quality manner require development to be able to describe health promotion to support adults with diabetes mellitus in behaving (Liang et al., 2011). 
Several efforts should emphasize the overall management that is covered in the form of $E M A S$ (education, nutrition management, physical activities, and stress management) interventions to change patient behavior in glucose control. It is a combination of the pillar of diabetes management, such as education, nutrition management, physical activity, and stress management to improve type 2 diabetes patients' behaviour to control blood glucose. Many previous studies have investigated a single intervention for diabetes management. However, limited studies have been focused on multi interventions to manage diabetes. Therefore, a study involving multi interventions which convey the pillars of diabetes management, such as EMAS interventions is highly needed.

\section{PURPOSE}

This research aims to analyse the effects of EMAS (education, nutrition management, physical activities, and stress management) nursing interventions on the knowledge, attitudes, skills, and glucose control among patients with type- 2 diabetes mellitus.

\section{METHODS}

\section{Research design}

This study used a quasi-experiment pre-post test without control group design for six months, from October 2018 to March 2019).

\section{Samples and setting}

This research was conducted in a village in Cimanggis District, Depok City. The study used a purposive sampling technique which obtained 86 respondents according to the criteria and the objectives of the study (Polit \& Beck, 2010). The inclusion criteria were patients with a medical diagnosis of type 2 DM, aged 35-59 years old, and being able to read and write. The exclusion criteria were patients with foot complications, diabetic, and bed rest.

\section{Research instrument and data collection}

According to the assessment of the psychometric properties of the Health-Related Quality of Life Instruments (HRQoL), this research used the EuroQoLfive-dimensional (EQ-5D) scale instrument. EQ-5D was scored using assessments derived from the UK general population survey with the domains contained in the patient's self-care and what activities are normally done. The brief diabetic knowledge test in questionnaire format developed by the University of Michigan Diabetes Research and Training Center and the attitude toward self-care questionnaire based on the diabetic care profile were used.

The EMAS interventions were carried out in 8 sessions where each session was around 30 minutes long. The data collection processes were as follows; 1) selecting research subjects that were adjusted to the inclusion criteria; 2) providing research information clearly to the research subjects; 3 ) requesting the respondent's approval to be the subject of research by providing an informed consent sheet; 4) determining the groups of research subjects which were divided into seven groups; 5) completing pre-test questionnaire to all respondents; and 6) measuring post-test after EMAS interventions were finished. The intervention activities are presented in Table 1. 
Table 1. Schedule of EMAS (education, nutrition management, physical activity, stress management) interventions

\begin{tabular}{|c|c|c|}
\hline Session & Activities & Method \\
\hline Session 1 & Diabetes education & $\begin{array}{l}\text { Watching educational videos, discussions, } \\
\text { and evaluation of workbooks which was } \\
\text { held once in the first week of November. }\end{array}$ \\
\hline Session 2 & $\begin{array}{l}\text { Health screening: risk factors } \\
\text { screening for diabetes mellitus }\end{array}$ & $\begin{array}{l}\text { The support group method by health cadres } \\
\text { to the community, demonstration, and re- } \\
\text { demonstration on the google form filling } \\
\text { training for health cadres which were held } \\
\text { twice in November. }\end{array}$ \\
\hline Session 3 & $\begin{array}{l}\text { Nutritional management: } \\
\text { healthy and unhealthy food for } \\
\text { diabetes patients }\end{array}$ & $\begin{array}{l}\text { The brief quiz method and evaluation of } \\
\text { workbooks which were held twice in the } \\
\text { third and fourth weeks of November. }\end{array}$ \\
\hline Session 4 & $\begin{array}{l}\text { Nutritional management: } \\
\text { calculating the body's calorie }\end{array}$ & $\begin{array}{l}\text { A tutorial that was held once in the first } \\
\text { week of December. }\end{array}$ \\
\hline Session 5 & $\begin{array}{l}\text { Nutritional management: } \\
\text { compiling a daily meal menu }\end{array}$ & $\begin{array}{l}\text { Demonstrations and re-demonstrations that } \\
\text { were held once in the second week of } \\
\text { December, as well as evaluating workbooks, } \\
\text { in the third week of January. }\end{array}$ \\
\hline Session 6 & $\begin{array}{l}\text { Increased exercise: Diabetic } \\
\text { foot exercises }\end{array}$ & $\begin{array}{l}\text { Demonstration and re-demonstration } \\
\text { methods carried out for five meetings in the } \\
\text { first, second, and third weeks of February, } \\
\text { and the first and second weeks of March. }\end{array}$ \\
\hline Session 7 & Increased exercise: Gymnastics & $\begin{array}{l}\text { Conducted with health cadres and the } \\
\text { community every week. }\end{array}$ \\
\hline Session 8 & $\begin{array}{l}\text { Progressive muscle relaxation } \\
\text { and music therapy }\end{array}$ & $\begin{array}{l}\text { Community nurse specialists conducting the } \\
\text { program for five meetings in the third week } \\
\text { of February until the third week of March. }\end{array}$ \\
\hline
\end{tabular}

\section{Data analysis}

Statistical tests for all analyses had a significance level of 95\% (alpha 0.05). A paired ttest was used to test the differences between the two dependent variables.

\section{Ethical consideration}

The study was approved by the research ethics committee from the Faculty of Nursing, University of Indonesia, number 62/UN2.F12.D/HKP.02.04/2018.

\section{RESULTS}

The characteristics of respondents in this study included gender, education, sources of information about DM, income, and the age. Table 1 shows that the majority of the respondents were women, graduated from junior high school, not getting information from anyone, and having income under the minimum wage. The mean age was 45.70 years. 
Table 2. The characteristics of respondents $(n=86)$

\begin{tabular}{lcc}
\hline \multicolumn{1}{c}{ Characteristics of respondents } & \multicolumn{2}{c}{ Intervention $(\mathrm{n}=86)$} \\
\cline { 2 - 3 } & \multicolumn{2}{c}{$\%$} \\
\hline Age & \multicolumn{2}{c}{$45.70 \pm 6.928$} \\
(Mean+SD) & 34 & \\
Gender & 52 & 39.5 \\
$\quad$ Man & & 60.5 \\
$\quad$ Woman & 8 & \\
Education & 15 & 9.3 \\
$\quad$ No school & 19 & 17.4 \\
$\quad$ Not graduated from primary school & 24 & 22.1 \\
$\quad$ Graduated from elementary school & 18 & 27.9 \\
$\quad$ Graduated from junior high school & 2 & 20.9 \\
$\quad$ Graduated from high school & & 2.4 \\
$\quad$ College & 18 & 20.9 \\
Sources of information about DM & 23 & 26.7 \\
$\quad$ Health workers & 21 & 24.5 \\
$\quad$ Family/friends & 24 & 27.9 \\
$\quad$ Media (TV/newspapers, internet, posters) & & \\
$\quad$ Not getting information from anyone & 62 & 72.1 \\
Income & 24 & 27.9 \\
$\quad$ Rp 3.565.660 & & \\
$\quad$ Rp 3.565.660 & & \\
\hline
\end{tabular}

Table 3 shows that the mean of knowledge and attitudes increased from 56.05 to 76.98 and from 22.14 to 33.36 , respectively, after the intervention. Similarly, the mean of skills increased from 5.51 to 7.13, while the mean of blood glucose decreased from $238.36 \mathrm{mg} / \mathrm{dl}$ to $231.63 \mathrm{mg} / \mathrm{dl}$ after the intervention. There were significant differences in knowledge, attitudes, skills $(p=0.001)$, and glucose control $(p=0.04)$ of type- 2 diabetes after the interventions.

Table 3. Knowledge, attitude, skill, and glucose type 2 diabetic patients $(n=86)$ before and after the interventions

\begin{tabular}{lcccc}
\hline Variable & Mean & SD & $95 \%$ CI & p-value \\
\hline Knowledge & & & & \\
$\quad$ Before & 56.05 & 16.61 & $(-8.015)-(-7.148)$ & 0.001 \\
$\quad$ After & 76.98 & 11.59 & & \\
Attitudes & & & & \\
$\quad$ Before & 22.14 & 4.46 & $(-12.360)-(-10.081)$ & 0.001 \\
$\quad$ After & 33.36 & 2.63 & & \\
Skills & 38.59 & 1.70 & $(-13.428)-(-9.154)$ & 0.001 \\
$\quad$ Before & 49.88 & 0.94 & & \\
$\quad$ After & & & $(0.196)-(13.270)$ & 0.04 \\
Glucose & 238.36 & 79.48 & & \\
$\quad$ Before & 231.63 & 65.79 & & \\
After & & & & \\
\hline
\end{tabular}




\section{DISCUSSION}

The results of this study showed that EMAS had a significant effect on knowledge, attitudes, skills, and glucose control of type 2 diabetic patients. Knowledge, attitudes, and skills of a person would increase if he or she was carried out mentoring to give an activity or a way to stimulate themselves in the form of activities that trigger to raise their awareness. As an example, in this case, EMAS intervention was given to adults with diabetes mellitus specifically to increase self-awareness and then create good selfmanagement for their care. Therefore, it is indeed necessary to have a nursing intervention in the health care system given to adults of type 2 diabetes mellitus with efforts to promote and prevent disease control. There are several reasons why the EMAS intervention could increase KSB and control glucose level.

The EMAS intervention provides education to promote healthy living that needs to be done as a part of efforts to prevent and control diabetes mellitus. The International Diabetes Association believes that to prevent the complications of diabetes or disease from being more sustainable, the need for health education for the behaviour of selfmanagement of people with diabetes should be promoted (Lari et al., 2017). Healthrelated research found that Diabetes Self-Management Education (DSME) plays a crucial role in empowering people with diabetes to engage and maintain lifestyle changes, which have been shown to improve health outcomes. DSME is a process of facilitating the knowledge, skills, and abilities needed for self-management. DSME needs to be done on people with diabetes regularly, which is also in line with the Ministry of Health program (Fan, Cde, \& Sidani, 2018).

In addition to the health education provided in EMAS interventions, the interventions also combine nutrition management, which included diet, recommended, restricted, and avoided foods, calculating the body's caloric needs, and compiling a meal menu each day. The principle of eating regulation for people living with diabetes is almost the same as the recommended diet for the general public, namely food that is balanced by the calorie and nutritional needs of each individual. Adults' diabetes mellitus needs to be emphasized on the importance of regular eating schedules, type, and amount of calorie contents, especially in those who use drugs that increase insulin or insulin therapy itself (Zamani-alavijeh, Araban, Mohammadi, \& Goodarzi, 2017). This nutrition management intervention also has the same results as research related to nutritional counseling for people with type 2 diabetes and has been shown to increase respondents' knowledge and skills in measuring balanced nutrition (Herring, Beckett, Stanton-robinson, \& Witry, 2018).

Physical activities were also included in the intervention after giving nutrition management for five meetings. Physical activities reported by the World Health Organization are carried out regularly 3-5 times a week for at least 30 minutes, with a total of 150 minutes per week, and a training break of no more than two consecutive days. When doing exercise, it is recommended to examine the glucose level before the exercise begins (Alghafri et al., 2017). If the blood glucose level is $<100 \mathrm{mg} / \mathrm{dL}$, the patients must consume carbohydrates first, and if it is $>250 \mathrm{mg} / \mathrm{dL}$, the patients should delay the physical exercises. 
Lastly, stress management was also emphasized in the interventions. Increased risk of diabetes mellitus under stress conditions is caused by excessive production of the cortisol hormone. Excessive production of the cortisol hormone will affect to sleeplessness, depression, blood pressure increase, which will then make a person become weak and have excessive appetite. Therefore, a method to reduce the stress that occurs is needed (Awadalla et al., 2017). Stress management is effective in reducing stress levels and controlling blood sugar in diabetes mellitus by training progressive muscle relaxation and music therapy. Progressive muscle relaxation has various benefits. It can be seen from the results of previous studies related to the effects of progressive muscle relaxation with music and aromatherapy to reduce the level of stress among teachers (Dewi, Margawati, \& Mu'in, 2019). The same study about the effect of progressive muscle relaxation therapy also found that the therapy is very effective in reducing stress and blood sugar with a significant value of 0.003 (Guo et al., 2017).

The effect of EMAS innovation was also caused by various types of media and methods. The learning module is beneficial to be used as a tool for residency students to provide EMAS interventions to adult's diabetes mellitus and later can also be used by health workers in providing health education. Meanwhile, workbooks were given to adult's diabetes mellitus as a material for training when the intervention takes place. Modules and workbooks were written with the aim that health workers could provide appropriate interventions, and adults with diabetes mellitus could learn independently after getting direction from the cadres. This phenomenon in line with the previous research that by utilizing media tools in the form of module development for health workers, the results show that there is a positive reaction to the development of the module, and the post-training test results in the form of knowledge, attitudes, monitoring, and evaluation are higher than initial testability (Khaikleng, Wongwanich, Sriklaub, \& Ajpru, 2015). Family support is also necessary to realise, based on the results of research that the family empowerment affected family support in patients with type-2 DM (Luthfa \& Ardian, 2019).

The present study, however, still had limitations that it did not involve a control group, so there was no comparison group from the results of this study. Further research may employ a larger number of participants with a control group and a longer period of interventions. Nonetheless, this study has contributed to provide evidence for the nursing management of diabetes mellitus especially in the community.

\section{CONCLUSION}

The result showed that knowledge, attitudes, skills, and glucose control adults with type 2 diabetes mellitus increased after the implementation of EMAS (education, nutrition management, physical activity, and stress management) interventions. Thus, providing interventions should be adjusted to the management of the disease and the needs of the patients. Programs related to the promotive and preventive efforts need to be reviewed by paying more attention to the distinctive aspects of diabetes mellitus patients and the region as a pilot. The health office also needs to integrate health education provided to diabetes mellitus patients using a comprehensive method in accordance with DM management, and utilize a variety of media that are more interactive and applicable, both for health workers themselves and adults with diabetes mellitus who focuses on 
improving knowledge, attitudes, skills, and blood sugar controlling. Public health nursing services need to be established in order to increase the health services to be more precisely determine what interventions are following community problems.

\section{ACKNOWLEDGMENT}

The authors would like to thank all patients who participated in this study.

\section{CONFLICT OF INTEREST}

The authors declare no conflict of interest in this study.

\section{REFERENCES}

Ahdizadeh, M., Peymam, N., Taghipour, A., Esmaily, H., \& Mahdizade, S. (2013). Effect of health education program on promoting physical activity among diabetic women in Mashhad, Iran: applying social cognitive theory. Journal of Research in Health Sciences, 13(1), 90-7.

Al-Khalifa, A., Mathew, T. C., Al-Zaid, N. S., Mathew, E., \& Dashti, H. M. (2009). Therapeutic role of low-carbohydrate ketogenic diet in diabetes. Nutrition, 25(1112), 1177-1185. doi:10.1016/j.nut.2009.04.004

Alghafri, T. S., Alharthi, S. M., Al-balushi, S., Al-Farsi, Y., Al-busaidi, Z., Bannerman, E., ... Anderson, A. S. (2017). Health professionals' perceptions about physical activity promotion in diabetes care within primary health care settings in Oman. Heliyon, 3(12), e00495. doi:10.1016/j.heliyon.2017.e00495

Awadalla, H., Noor, S. K., Elmadhoun, W. M., Almobarak, A. O., Elmak, N. E., Abdelaziz, S. I., ... Ahmed, M. H. (2017). Diabetes complications in Sudanese individuals with type 2 diabetes: Overlooked problems in sub-Saharan Africa? Diabetes and Metabolic Syndrome: Clinical Research and Reviews, 11(suppl 2), S1047-S1051. doi:10.1016/j.dsx.2017.07.039

Ayele, K., Tesfa, B., Abebe, L., Tilahun, T., \& Girma, E. (2012). Self care behavior among patients with diabetes in Harari, Eastern Ethiopia: the health belief model perspective. PLoS One, 7(4), e35515. doi:10.1371/journal.pone.0035515

Darling-Fisher, C. S., Kanjirath, P. P., Peters, M. C., \& Borgnakke, W. S. (2015). Oral health: An untapped resource in managing glycemic control in diabetes and promoting overall health. Journal for Nurse Practitioners, 11(9), 889-896. doi:10.1016/j.nurpra.2015.08.001

Dewi, C. F., Margawati, A., \& Mu'in, M. (2019). Effects of progressive muscle relaxation intervention with music and aromatherapy on decreasing stress level among teachers. Nurse Media Journal of Nursing, 8(2), 71-78. doi:10.14710/nmjn.v8i2.20681

Dwi, A., Amatayakul, A., \& Karuncharernpanit, S. (2017). Predictors of diabetes selfmanagement among type 2 diabetics in Indonesia: Application theory of the health promotion model. International Journal of Nursing Sciences, 4(3), 260265. doi:10.1016/j.ijnss.2017.06.010

Fan, L., Cde, R. N., \& Sidani, S. (2018). Factors influencing preferences of adult with type 2 diabetes for diabetes self-management education interventions. Canadian Journal of Diabetes, 42(6), 645-651. doi:10.1016/j.jcjd.2018.04.003

Guo, W., Zhu, H., Wang, Z., Chen, J. A., Wu, J., Zhu, Y., \& Gu, X. (2017). Novel rhynchophylline analogues as microvascular relaxation agents for the treatment of 
microvascular dysfunction caused by diabetes. European Journal of Medicinal Chemistry, 139, 657-664. doi:10.1016/j.ejmech.2017.08.026

Herring, M. S., Beckett, E. A., Stanton-robinson, C. A., \& Witry, M. J. (2018). What do I eat? Impact of an interactive teaching method for improving pharmacy students ' diabetes nutrition knowledge and comfort in providing nutrition counseling. Currents in Pharmacy Teaching and Learning, 10(7), 918-24. doi:10.1016/j.cptl.2018.04.015

Jeong, J., \& Yu, J. (2018). Prevalence and influencing factors of metabolic syndrome among persons with physical disabilities. Asian Nursing Research, 12(1), 50-55. doi:10.1016/j.anr.2018.02.001

Joiner, K. L., Nam, S., \& Whittemore, R. (2017). Lifestyle interventions based on the diabetes prevention program delivered via eHealth: A systematic review and meta-analysis. Preventive Medicine, 100, 194-207. doi:10.1016/j.ypmed.2017.04.033

Khaikleng, P., Wongwanich, S., Sriklaub, K., \& Ajpru, H. (2015). A training module for evaluation capacity building of a health support organisation in Thailand. Procedia Social and Behavioral Sciences, 171, 1395-1399. doi:10.1016/j.sbspro.2015.01.259

Lari, H., Tahmasebi, R., \& Noroozi, A. (2017). Diabetes \& metabolic syndrome: Clinical research \& reviews effect of electronic education based on health promotion model on physical activity in diabetic patients. Diabetes \& Metabolic Syndrome: Clinical Research \& Reviews, 12(1), 45-50. doi:10.1016/j.dsx.2017.08.013

Liang, X., Wang, Q., Yang, X., Chao, J., Chen, J., Mo, X., ... Gu, D. (2011). Effect of mobile phone intervention for diabetes on glycaemic control: a meta-analysis. Diabetic Medicine, 28(4), 455-63. doi:10.1111/j.1464-5491.2010.03180.x

Luthfa, I., \& Ardian, I. (2019). Effects of family empowerment on increasing family support in patients with type-2 diabetes mellitus. Nurse Media Journal of Nursing, 9(1), 58-68. doi:10.14710/nmjn.v9i1.22501

Mohebi, S., Parham, M., Mozafarion-Pour, E., \& Kamran, A. (2014). Self-care assessment in patients with diabetes in Qom city in 2013. Archives of Hygiene Sciences, 3(4), 167-176.

Polit, D. F., \& Beck, C. T. (2010). Essentials of nursing research appraising evidence for nursing practice (Seventh Ed). China: Library of Congress Cataloging in Publication Data.

Ministry of Health Republic of Indonesia. (2016). Info datin: Waspada diabetes [Datin information: Beware of diabetes]. Retrieved November 12, 2018, from https://pusdatin.kemkes.go.id/folder/view/01/structure-publikasi-pusdatin-infodatin.html

Ministry of Health Republic of Indonesia. (2018). Riset kesehatan dasar tahun 2018kementerian kesehatan [Basic health research 2018-ministry of health]. Retrieved from https://www.depkes.go.id/resources/download/info-terkini/materi_rakorpop _2018/Hasil\%20Riskesdas\%202018.pdf

Wang, L.W., Ou, S.H., Tsai, C.S., Chang, Y.C., \& Kao, C.W. (2016). Multimedia exercise training program improves distance walked, heart rate recovery, and selfefficacy in cardiac surgery patients. The Journal of Cardiovascular Nursing, 31(4), 343-349. doi:10.1097/JCN.0000000000000246 
Wattanakul, B. (2012). Factors influencing diabetes self management behaviors among patients with T2DM in rural Thailand (Unpublished Doctoral Dissertation). University of Illinois Chicago, Chicago, United States.

Zamani-alavijeh, F., Araban, M., Mohammadi, V., \& Goodarzi, F. (2017). Development and psychometric evaluation of a new instrument to assess nutritional perceptions and behaviors of diabetic men. Diabetes and Metabolic Syndrome: Clinical Research and Reviews, 119(Suppl 2), S949-S955. doi:10.1016/j.dsx.2017.07.021 